\title{
Crianças, adultos e hackers: cotidianos e tecnologias
}

\begin{abstract}
Resumo: Este artigo tem como objetivo discutir os cotidianos infantis compartilhados com os adultos, diante da perspectiva da cultura digital e das práticas hackers desenvolvidas a partir da proposta de interação com participantes do projeto Crianças Hackers e em seus cotidianos familiares. A palavra hacker é tomada em seu sentido originário referindo-se a pessoas com forte interesse em tecnologias cuja curiosidade impulsiona suas atitudes de forma lúdica. Os objetivos específicos estão em descrever e analisar as práticas de aprendizagem compartilhada entre crianças e pessoas adultas, diante de conteúdos relacionados a tecnologias em sentido amplo, e na construção e reflexão sobre essas vivências a partir de seus cotidianos na interação com a cultura digital. Como construtos da pesquisa participante, tomada como um momento dinâmico dentro das ações realizadas, apresentamos relatos de atividades e vivências nos quais as crianças protagonizam a reinvenção não apenas dos espaços físicos que passam por reestruturações, mas também dos modos de ser e fazer dos adultos que precisam refletir e reconstruir suas práticas na relação com os pequenos. Como resultados podemos mencionar a necessidade urgente de repensar os espaços educativos formais, para que valorizem as experiências cotidianas das crianças e estejam mais atentos às dinâmicas contemporâneas, que envolvem além da inserção de tecnologias digitais, as maneiras outras de pensar, fazer, relacionar, ser, construir e compartilhar conhecimentos.
\end{abstract}

Palavras-chave: Crianças. Aprendizagem. Cultura. Tecnologia. Hackers

\section{Como fazer uma bola de chiclete gigante: cotidianos, tecnologias e criatividade}

Este artigo trata da vivência partilhada entre adultos e crianças, tendo como base o acesso às tecnologias e ao conhecimento como um direito de pessoas de todas as idades. Para isso, abordamos três conceitos: cultura digital, ludicidade e hackers. Pretendemos mostrar o quanto esses conceitos se conectam através de práticas significativas e necessárias, cotidianamente, para valorizar a infância e o direito ao aprender na contemporaneidade em todas as fases da vida.

O convívio com crianças nos mostra que estas possuem formas diversas de se expressarem e interpretarem o mundo, através da linguagem verbal e não verbal. Contudo, para traduzir essa percepção em práticas, é necessário a decisão de se libertar
Karina Moreira Menezes Universidade Federal da Bahia karina.menezes@ufba.br

Salete de Fátima Noro Cordeiro Universidade Federal da Bahia salete.noro@ufba.br 
da visão adultocêntrica sobre o saber e a cultura infantil. Para se desenvolverem em suas potencialidades, as crianças precisam encontrar abertura para experienciar as informações e a cultura que as cerca, e isso se dá no cotidiano, ou seja, não apenas em casa, não apenas na escola, mas em todos os locais nos quais a criança permanece. Pensar o convívio entre crianças e adultos, nessa perspectiva, é a todo tempo desafiador e estimulante para aprender a ver o mundo e a educação de maneiras como não imaginávamos antes.

Quando não impomos nosso jeito de pensar tão preconcebido, estamos nos desafiando a reinterpretar aquilo que sabemos, o que aprendemos e o jeito como ensinamos em momentos bastante inusitados. Como exemplo, trazemos uma conversa com Ian, que na época estava com sete anos. Ele e a mãe brincavam de fazer bolas de goma de mascar distraidamente, quando o menino perguntou: - "Quantos chicletes tenho que mastigar se eu quiser fazer uma bola desse tamanho?" e abriu os braços o máximo que pôde mostrando o tamanho da bola pretendida. Tal pergunta já sinalizava para vários conhecimentos prévios construídos ao longo de sua jovem vida, como por exemplo, as ideias de adição e de proporção. Mãe e filho fizeram algumas especulações sobre a pergunta, tomando como padrão de medida suas próprias mãos. Ian comparou o tamanho do chiclete mascado com seu dedo mindinho (sim, ele tirou o chiclete da boca) e logo depois voltou a mastigá-lo para fazer a maior bola possível, que media, aproximadamente, a palma da sua mão aberta. Logo ele percebeu que para fazer uma bola de chiclete gigante precisaria de uma boca bem maior, uma boca de gigante, para mascar muito chiclete ao mesmo tempo. Se mãe e filho quisessem explorar tal situação do ponto de vista didáticopedagógico, poderiam adotar o experimentalismo, enchendo a boca de chicletes e fazendo bolas, ou poderiam adotar a dedução e ilustrar a situação em papel, o que acionaria linguagens e expressões outras, muito além do ato de mascar.

Um outro exemplo temos quando Felipe, de dez anos, que mostrava todo seu interesse em ciências, junto ao gosto por locomotivas, personagens, games e brinquedos de construir. $\mathrm{Na}$ internet, ele buscava vídeos de experimentos e não raro, a mãe e o pai encontravam coisas estranhas na geladeira: um pote com uma mistura colorida, uma massinha com aspecto estranho enrolada em plástico, substâncias congeladas, entre outros. Ao se atentar 
para esses episódios, a mãe o alertou para algumas questões de segurança quanto ao uso de alguns produtos e utensílios e colocou um limite: "usar fogo, somente com supervisão". Essas situações são exemplos de cotidianos nos quais as pessoas adultas estão abertas a dialogar com as crianças e permitir que essas experimentem sua própria curiosidade, o que pode ser proveitoso, apesar de desafiador.

As duas crianças aqui citadas são filhos das pesquisadoras e algumas experiências descritas são relatos da interlocução deles em seus círculos de amizades, registradas pelas mães ao longo do tempo, pois seus contextos de estudo e pesquisas despertavam a inquietação diante de diversas situações surgidas no cotidiano de vida de seus pequenos. Como diz Certeau (1998, p.31):

O cotidiano é aquilo que nos é dado cada dia [...] nos pressiona dia após dia, nos oprime, pois existe uma opressão no presente. [...] Cotidiano é aquilo que nos prende intimamente, a partir do interior. É uma história a meio caminho de nós mesmos, quase em retirada, às vezes velada.

Falar sobre cotidiano na atualidade implica, também, falar sobre tecnologias, notadamente das tecnologias digitais, pois "[...] são poucas e declinantes as formas de agir e se comunicar nos grandes centros urbanos que não passem, em algum momento da sua cadeia produtiva, pela onipresença do chip". (CAZELOTO, 2008, p. 80) De tal forma, crianças e adultos convivem, direta ou indiretamente, com essas tecnologias, naturalizando a existência e a influência delas em suas vidas. No momento em que o digital passa a existir e fazer parte de seu cotidiano, elas desenvolvem modos de usufruírem dessa tecnologia, criando e recriando artefatos, objetos, maneiras de produzir, de conhecer, de fazer, de pensar, de relacionar, de gerar outras técnicas e tecnologias a partir das primeiras. Contudo, Cazeloto (2008) afirma que a informatização do cotidiano consiste na penetração de máquinas e equipamentos informatizados na sociedade atrelada ao processo de banalização das relações humanas mediadas por esses equipamentos, sem que haja um investimento na formação crítica da sociedade. Além disso, tecnologias digitais estruturam a base econômica da sociedade contemporânea e há bens materiais e culturais acessíveis exclusivamente através delas. Logo, o acesso aos artefatos tecnológicos deve ser amplo e aberto, ao contrário do que se observa nos dias de hoje. 
Reconhecemos a dificuldade em assegurar que as crianças e jovens tenham acesso a conteúdos e dinâmicas do digital que contemplem sua faixa etária, seus interesses e necessidades de desenvolvimento, tendo como agravante o fato de que o acesso à infraestrutura tecnológica é tão desigual quanto são desiguais as garantias de direitos básicos. Relatórios do Comitê Gestor da Internet no Brasil (Cetic.br) em 2016, indicavam aumento no número de domicílios com acesso à internet, com incremento para o uso de aparelhos portáteis como notebooks e tablets. Por outro lado, os indicadores também mostram a variação socioeconômica e geopolítica, cujos menores índices de acesso estão nas zonas rurais e nas classes sociais com menor poder aquisitivo, de tal forma que enquanto mais de $91 \%$ das famílias economicamente favorecidas (classes A e B) e 60\% dos domicílios da classe média (classe C) têm acesso à internet em casa, menos de 24\% das famílias das classes D e E contam com esse acesso. Esses dados mostram as desigualdades discrepantes de acesso em relação à infraestrutura, o que não impossibilita que essas comunidades ou coletivo organizem-se para vivenciarem espaços alternativos de cultura digital e escreverem sua história.

A necessidade de criar espaços nos quais crianças e adultos pudessem aprender juntos com e sobre tecnologias, deu origem ao projeto Crianças Hackers criado por mães participantes de um laboratório tecnológico comunitário chamado Raul Hacker Club, em Salvador/BA, um espaço coletivo no qual pessoas interessadas em tecnologias se reúnem para desenvolver projetos juntos, de forma colaborativa e voluntária. O termo hacker faz alusão ao sentido originário da palavra, referindo-se a pessoas com profundo conhecimento tecnológico, que pensam e agem de forma diferente do convencional e que compartilham aquilo que fazem e aprendem com sua comunidade, sendo mobilizados pela sua curiosidade e pela paixão. (MENEZES, 2018) Coerente com a cultura hacker, os encontros do projeto Crianças Hackers visam disseminar o aprendizado tecnológico de forma lúdica e compartilhada entre adultos e crianças fazendo parte do nosso campo de observação.

Portanto, diante dos cotidianos que observamos e investigamos, percebemos que as crianças são curiosas, atentas, questionadoras, compartilham o que sabem, inclusive as próprias dúvidas. Sendo assim, em nosso entender, crianças são hackers em potencial, mas os cotidianos instituídos não permitem que elas se desenvolvam como 
sujeitos criativos e colaborativos, na medida em que a curiosidade The é cerceada. Um desses cotidianos instituídos é o da escola, local por excelência de formação das crianças e das juventudes. Escolas têm, historicamente, mantido modelos, teorias e práticas anacrônicas em relação às mudanças sociais, aos interesses de seus membros, e têm colonizado seus espaços e tempos com propostas massificadoras, com uma dinâmica que mistura padronização e hierarquização de ritmos, negligenciando as necessidades, ritos e dinâmicas trazidos pelos aprendizes e professores. Apesar de terem sido contempladas com políticas públicas no campo das tecnologias digitais, nas últimas décadas, como implementação de laboratórios de informática, distribuição de netbooks para alunos, lousas digitais, tablets, dispositivos de acessibilidade e conectividade, não mudaram os princípios e as concepções do educar, e continuam a pautar seu currículo na padronização e rigidez em relação a conteúdos, tempos e espaços de aprender.

Essa mesma hierarquização e centralização do saber encontramos em cotidianos da instituição família, quando os adultos, por diversos motivos, não oferecem às suas crianças, oportunidades de questionar, de vivenciar experiências significativas, diversificadas, e com isso investigar a realidade que as rodeia, ampliando seus horizontes de observação e experimentação.

Nossa inquietação está em conhecer e promover formas através das quais as crianças articulam, recriam e vivenciam as diferentes redes de aprendizagens e trocas onde se inserem, tendo as tecnologias como espaço estruturante. Temos, portanto, como objetivo, discutir e compreender o alcance das tecnologias digitais nos processos sociais compartilhados por adultos e crianças em práticas criativas e colaborativas, possíveis de serem alcançadas em espaços escolares e não escolares.

Para buscar respostas a essa e outras inquietações, não podemos nos limitar a cenários nos quais as tecnologias são abundantes, assim como não podemos permanecer em posturas contemplativas. De tal modo, o ativismo hacker - que defende o acesso às tecnologias como condição para acesso livre ao conhecimento - surgiu como potencialidade de convergência de práticas colaborativas, estendendo-se a outros campos de atuação e conhecimento.

A metodologia pautou-se em uma abordagem qualitativa, através de pesquisa participante dado seu viés ativo, com a qual 
buscamos dispositivos para observação direta nos cotidianos no quais as crianças estavam inseridas: escola, laboratório de tecnologias e cotidiano familiar. Para as teorias do cotidiano, o método é um processo de construção que foge a uma condição de estabelecimento de objetividade e estruturas prévias. Segundo Pais (2003, p. 30):

Em que consiste a perspectiva metodológica do cotidiano? Precisamente em aconchegar-se ao calor da intimidade da compreensão, fugindo das arrepiantes e gélidas explicações que, insensíveis às pluralidades disseminadas do vivido, erguem fronteiras entre os fenômenos, limitando ou anulando as suas relações recíprocas.

É nesse cotidiano que se misturam a vida do ser educador, ser mãe, ser pai, ser profissional, ser criança, ser escolar, cotidianos estes que se emaranham e afetam-se com afastamentos e com aproximações, o que pode ser observado principalmente diante das tecnologias contemporâneas e da cultura digital, cujos códigos, símbolos e funcionamentos são ainda desconhecidos de muitos adultos e crianças por aí.

Portanto, a pesquisa participante, tal como proposta por Carlos Rodrigues Brandão e Borges (2007), é coerente com os estudo do cotidiano pois sua característica principal é a diferenciação visto que não cabe nela "uma única teoria, um único método de trabalho e nem mesmo um único horizonte de ação social." (BRANDÃO; BORGES, 2007, p. 56) Reitera-se ainda que a coexistência das funções de mães e de pesquisadoras, traz singularidade ao método devido à participação orgânica das pesquisadoras em relação aos sujeitos, imersos em seus respectivos cotidianos.

\section{Intercâmbios de papéis na cultura digital}

A inversão de papéis em relação aos saberes tecnológicos no cotidiano é cada vez mais evidente. A fluência com a qual crianças utilizam aparelhos digitais faz com que se tornem técnicos experientes diante de seus progenitores. Quem de nós ainda não viu uma pessoa adulta precisar da ajuda de uma criança ou de um jovem para configurar um aparelho de TV ou baixar um novo aplicativo (app) no smartphone? Nesses casos, são as crianças e os jovens quem nos ensinam - ou fazem por nós - a comunicação 
com os artefatos digitais, sendo também protagonistas da cultura digital. A cultura digital é resultante de práticas sociais e humanas desenvolvidas a partir dos processos de digitalização. É a partir do desenvolvimento da tecnologia digital, da aproximação cada vez mais intensa dos praticantes/interagentes em ter acesso, em manipular, em vivenciar, em compreender melhor essas tecnologias, que vai sendo construída a cultura digital. (CORDEIRO, 2014) O digital passa a permear todo o cotidiano envolvendo captura, produção, processamento e compartilhamento de diversos tipos de conteúdos, o que passa a marcar a sociedade atual.

A cultura digital é intensa e profunda, modifica os diferentes âmbitos de nossa vida em sociedade qualificando, então, a cultura em seu todo. Nesse sentido, quanto mais presente e transformadora for, mais rápido e intensamente é incorporada a nossa vida, não havendo mais a necessidade de adjetivar a cultura como digital, passaremos a nos referir, com o passar do tempo, apenas à cultura. Geertz (2008, p. 4), afirma que "[...] o homem é um animal amarrado em teias de significados que ele mesmo teceu" (GEERTZ, 2008) e, assim, entende a cultura como sendo essas teias e a busca de seus significados. Esse autor afirma que "[...] a cultura não é um poder, algo ao qual podem ser atribuídos casualmente os acontecimentos sociais, os comportamentos, as instituições, ou os processos; ela é um contexto, algo dentro do qual eles podem ser descritos de forma inteligível". (GEERTZ, 2008, p. 10) Então, podemos compreender a cultura como constituída a partir de práticas sociais, que a modificam, ora transformando as maneiras de pensar, de construir, de criar, de trabalhar, de relacionar, de viver e de construir ou reconstruir a própria cultura.

Nesse contexto de transformação surgem as gerações que já nascem imersas em conteúdos e práticas de cultura digital: crianças nascidas desde as últimas décadas do século passado, passam a vivenciar um cotidiano, onde a linguagem predominante é a digital. São dispositivos móveis, nos quais a convergência de tecnologia está presente de maneira intensa: é possível atualmente, um mesmo aparelho dispor de câmera que filma e fotografa, gravador de áudio, aplicativos de edição, games, canais de vídeos, mensageiros instantâneos etc.

A comunicação é muito potente, crianças e jovens podem acessar conteúdos ou mesmo produzi-los, editá-los e em seguida compartilhá-los a partir de um mesmo dispositivo. Surge nesse 
momento a dimensão da autoria e do protagonismo na construção de conhecimentos. Como diz Pretto (2011, p. 107) "[...] a apropriação que a juventude vem fazendo desses aparatos tecnológicos tem lhe possibilitado ir além do mero consumo de informações: ela está produzindo intensamente culturas e conhecimentos." E esse processo é decorrente de todo o contexto da cultura digital, permeado por infraestrutura de conectividade e suportes digitais, das relações que vão se estabelecendo a partir de contextos, onde colaboração e compartilhamento fortalecem redes de construção de saberes e conhecimentos.

As relações espaço-temporais são alteradas, e ao tratar sobre cotidiano é indispensável trazer para a reflexão o espaço e o tempo, pois é a partir deles que aquele ganha vida, desenvolve-se e pode ser compreendido. Espaço e tempo apresentam-se como significantes, onde as relações entre os sujeitos acontecem, onde se constituem os jogos de força em permanente mobilização e conflito pelos quais os sujeitos praticantes produzem e se autoproduzem nas inter-relações que estabelecem, na tessitura do dia a dia, com o outro e com todos os elementos que se apresentam como oportunidade de algum tipo de ganho. Essas dimensões outras, ou potencialidades que a cultura digital traz consigo, tem possibilitado às crianças e jovens o acesso síncrono e assíncrono aos ambientes digitais, à comunicação e produção de diversos tipos de conteúdos, o que modifica completamente sua relação com os processos de aprendizagem e a construção de conhecimentos.

Os espaços formais onde era buscado o conhecimento são tensionados, pois as possibilidades de compartilhamento são alargadas, diversificadas, escolhidas dentre um menu de opções muito mais atrativas, com linguagens intuitivas e, portanto, acessíveis em vários idiomas e plataformas.

\section{Os hackers e o lúdico}

Hackers não são criminosos digitais tal como se popularizou no imaginário social. A origem do termo "hacker" vem do verbo em inglês tohack cujo significado é esculpir, entalhar. Ao se acrescentar a partícula "er", se refere ao entalhador, o artista que transforma a madeira em arte, e começou a ser usada como um elogio aos integrantes do The Tech Model Railroad Club (TMRC), um clube de ferromodelismo do Massachusetts Institute of Technology (MIT) 
que, já na década de 50, se dedicavam a desenvolver locomotivas e aparelhagens de controle para o tráfego nas maquetes. Quando bonita e inovadora, a produção era considerada como um hacking. No MIT, o hacking era associado a brincadeiras do tipo "pegadinhas" criativas e inusitadas, bem como era considerado um hacking se aventurar caminhando por trilhas e caminhos pouco frequentados no terreno do instituto. De tal forma, o termo hackear guarda em si esse sentido de ser algo desafiador, divertido, inovador e criativo, cujo resultado é compartilhado com outras pessoas.

A cultura do hacking foi disseminando-se em diferentes gerações, envolvendo cada vez mais pessoas interessadas no desenvolvimento tecnológico iniciado nos anos 1960 e 1970, época em que computadores eram raros e caros, e tendo maior ampliação a partir das décadas de 1980 e 1990, quando as ações realizadas por jovens aficionados por tecnologias começaram a configurar-se como delitos, pois, guiados pela curiosidade e gosto pelo desafio, desenvolveram técnicas que permitiam burlar o funcionamento de aparelhos de comunicação e explorar fragilidades nos sistemas informáticos. Atos criminosos não eram a tônica desses sujeitos, tanto que estudos sistematizados sobre a cultura e a ética hacker apontam para princípios e valores partilhados por indivíduos e por grupos de hackers dentre os quais destacamos o cuidado com o outro, a abertura na troca de conhecimento, o valor social construído pelo reconhecimento de suas ações, a liberdade de ser, a privacidade no fazer, a curiosidade como guia, a criatividade como marca, tudo isso mobilizado pela paixão pelo que se deseja realizar. (MENEZES, 2018; HIMANEN, 2001)

A partir dos anos 2000, observamos a emergência de locais físicos nos quais a atual geração de hackers se encontra presencialmente e nesses locais, convivem pessoas de diferentes áreas de conhecimento. Ao analisar as motivações que levam pessoas a participar de espaços hackers, Moilanen (2012, p. 17) destaca que "[...] divertir-se é um dos fatores de motivação mais importantes e a diversão é uma parte fundamental da vida social". A relação intrínseca entre diversão e vida social é explicitada por Eric Raymond (2001) ao afirmar que "para os hackers de verdade, todas as fronteiras entre 'jogo', 'trabalho', 'ciência' e 'arte' tendem a desaparecer ou a fundirem-se em um jogo de alto nível criativo", pois "trabalhar tão intensamente quanto você joga e jogar tão intensamente quanto você trabalha" (RAYMOND, 
2001) é uma máxima que define a visão da interdependência entre o lúdico e o hackerismo.

Como diz Gilles Brougère (2011, p.21) uma das características do jogo está em "[...] não dispor de nenhum comportamento específico que permita separar claramente a atividade lúdica de qualquer outro comportamento. O que caracteriza o jogo é menos o que se busca do que o modo como se brinca, o estado de espírito com que se brinca." Por outro lado, essa definição de Brougère abarca parcialmente o jogo no hackerismo, pois o resultado é tão importante quanto o processo. Tal como nos aponta a fala inicial de Eric Raymond, a necessidade do jogo faz parte do modo de aprender hacker, do seu modo de produzir, não sendo, portanto, algo supérfluo, limitado ou isolado de sua vida cotidiana. Nesse sentido, a ludicidade é toda uma ambiência organizada dentro de lógicas próprias que se associam à afetividade pelo jogo e pelo brincar e, no hackerismo, o lúdico é um estado de espírito que evoca uma profunda afetividade vislumbrada na paixão pelo que se faz e pelo desafio de continuar fazendo. (MENEZES, 2018, p.135)

$\mathrm{Na}$ cultura hacker, fala-se e vive-se em torno de projetos de interesse dos participantes. Esse foi um dos fatores que motivou uma das autoras a levar o filho consigo, para frequentar o espaço do Raul Hacker Club. Esses espaços são usualmente pensados para adultos, mas o Raul Hacker Club foi aos poucos sendo adaptado para incluir as crianças de forma segura e acolhedora. Tal atitude evidencia a busca pelas práticas culturais contemporâneas, demonstrando que a atenção dos participantes está voltada para a relação que eles estabelecem com os artefatos da cultura e não apenas com os bens materiais em si.

É, portanto, durante essas práticas culturais que Certeau (2008) vai encontrar as operações e usos individuais, suas relações, seus percursos, o efêmero, o inusitado, os desvios. Ele vai desvelar o que está além da cultura erudita e da cultura popular. Mostra-nos, a partir da análise das práticas cotidianas, uma "antidisciplina", que seriam as "táticas" dos praticantes. Isso fica explícito, quando a mãe leva seu filho para um espaço que ela considera lugar de adultos, um local de transgressão em relação aos espaços instituídos. Aos 3 anos, Ian reclamava do fato de estar de férias, fazendo menção ao desejo de voltar logo para a escola para encontrar colegas e amigas e amigos. Essa situação incentivou sua mãe a criar o projeto Crianças Hackers nas instalações do Raul Hacker Club, como forma 
de oferecer ao seu filho a possibilidade de estar junto com outras crianças brincando com a desmontagem de artefatos tecnológicos. Aqui podemos perceber a arte das táticas, aquelas praticadas pelos sujeitos comuns, no caso aqui a mulher, mãe e trabalhadora, que vivencia o dia a dia subvertendo a ordem estabelecida, tentando sobreviver através das brechas, ao criar espaços alternativos de sobrevivência.

Não tem sido fácil ser mãe, mulher, professora, na contemporaneidade, pois a jornada de trabalho das mulheres usualmente é intensa e sobreposta por várias responsabilidades que lhes são social e historicamente imputadas. No Censo do IBGE 2010, que nos reporta a estudo feito em 2006, encontramos no tópico "O trabalho da mulher, principal responsável no domicílio", a partir de dados coletados em seis regiões metropolitanas do país, a indicação que 2,7 milhões de mulheres são as principais responsáveis pelo sustento dos domicílios. O que chama atenção é que 50,6\% delas não tinham cônjuge e moravam com seus filhos, além de enfrentarem uma carga horária semanal longa de 39,2 horas.

Dados do IBGE de 2018 apontam que "[...] em 2016, as mulheres dedicaram aos cuidados de pessoas e/ou afazeres domésticos cerca de $73 \%$ a mais de horas do que os homens (18,1 horas contra 10,5 horas)" (IBGE, 2018) Quando é feito o recorte por região "verifica-se que a maior desigualdade na distribuição de horas dedicadas a estas atividades está na Região Nordeste, onde as mulheres dedicam cerca de $80 \%$ a mais de horas do que os homens". (IBGE, 2018, p. 3) Percebe-se a tripla jornada das mulheres que dividem seu tempo entre trabalho remunerado, afazeres domésticos e cuidado. Outro fator é a diminuição do tamanho das famílias, que cada vez menores, afasta a possibilidade de ter um membro encarregado de cuidar da criança pequena até que atinja a idade escolar, segundo Goldani (1993, p. 90-91):

O declínio do familismo como valor cultural é evidente e teria como origem o crescente individualismo e igualitarismo, características apontadas como marcas dos processos de modernidade pelo qual atravessa o país. O desaparecimento das famílias de três ou mais gerações, ou mesmo a diminuição dos parentes na residência de famílias conjugais são apontados como indicadores disto.

Agregado a esses fatores, o afastamento de familiares e parentes, traz mais desafios para o cuidado e a criação do filho. Diante de tal 
contexto, a mãe subverte a realidade dada, encontrando alternativas para solucionar o problema do filho estar em férias, longe da escola e dos colegas buscando alternativas de aproximá-lo de outras aprendizagens e outros colegas. Com o que lhe é dado, fabrica um espaço de convivência, entretenimento e aprendizagem "[...] instaura um presente relativo a um momento e a um lugar; estabelece um contrato com o outro [...] numa rede de lugares e relações". (CERTEAU, 2008, p. 40, grifo do autor) A mãe consegue subverter o que lhe é dado como determinado e reorganiza o cotidiano a seu favor, é o que Certeau chama de "maneiras de fazer", procedimentos populares ou quase imperceptíveis que subvertem a ordem estabelecida. "Essas 'maneiras de fazer' constituem as mil práticas pelas quais os usuários se reapropriam do espaço organizado pelas técnicas da produção sociocultural". (CERTEAU, 2008, p.41)

Entendemos o cotidiano como campo, onde se travam lutas pela sobrevivência e emancipação dos sujeitos praticantes, sendo, como salienta Ferraço (2008, p. 8), “[...] ponto de partida e de chegada de nossas lutas por transformar a realidade." O cotidiano passa a ser constituído na interação entre relações de poder e cultura num jogo de relações criadas pelos praticantes, nas tensões que se criam no dia a dia da vida ordinária. A necessidade de mãe e filho faz nascer um espaço relacional, um emaranhado de conexões e tramas de uma rede de múltiplas relações, espaços/ tempos interconectados de saberes, fazeres e práticas.

A mãe, temendo pelo desenvolvimento integral do seu filho no decorrer do processo de escolarização instituído na escola, e acreditando que o espaço hacker pode propiciar aprendizagens que a escola não pode oferecer naquele momento, pauta seu agir na hipótese de que a aproximação com tecnologias poderia ser um estímulo a curiosidade e desejo de continuar a aprender da criança, tendo clareza de que essa aproximação não pode se resumir ao manuseio superficial das telas touchscreen. Desse desafio, nasce um projeto que altera vários cotidianos.

\section{A presença das crianças no clube hacker: outras redes de aprendizagem}

$\mathrm{Na}$ cultura hacker, entretenimento significa algo muito interessante, capaz de mobilizar o sujeito a enfrentar desafios, instigar sua criatividade, mobilizar diversas faculdades mentais do 
praticante para que ele alcance seus objetivos. Portanto, a diversão não é algo imediato ou fugaz, ela pode ser tanto o meio quanto a meta e nem sempre isso é percebido a priori, afinal, quem pode afirmar se inventar um jogo é mais divertido do que jogá-lo?

Ao pensarmos o cotidiano estamos no campo do imprevisível, do não controlado, do desconhecido. No exercício da vida cotidiana, nos jogos que são estabelecidos, nada é planejado ou projetado com antecedência. As relações, as jogadas das/dos praticantes são dadas no presente, à medida que as possibilidades vão surgindo. Nada se guarda, como diz Certeau (2008), pois a cada momento são novas possibilidades e configurações da realidade que se manifestam, que exigem a astúcia e agilidade de articulação/decisão dos praticantes. Estes, não agem sozinhos. Estão imbricados em relações que se estabelecem de forma reticular. O cotidiano dá-se em meio às relações que se estabelecem num determinado espaço e tempo com o outro.

A presença de crianças em um ambiente tecnológico típico de adultos afeta a organização desse ambiente quanto a sua infraestrutura, os tempos e os discursos. Um exemplo dessa situação foi observado no Raul Hacker Club a partir do projeto Crianças Hackers, com a ação intitulada dia do Carimbador Maluco, que promovia a presença de crianças a partir de 3 anos na sede do clube. O nome Carimbador Maluco faz referência a uma música conhecida como "Plunct Plact Zoom", do roqueiro baiano Raul Seixas, cuja narrativa musical descreve um adulto que proíbe um grupo de crianças de realizar uma viagem espacial, impondo-lhes trâmites burocráticos para inviabilizar o intento. Contudo, o adulto se afeiçoa às crianças e, ao assumir que ele próprio gostaria de seguir com elas para aventurar-se pelo universo, ele permite que as crianças sigam sozinhas para a desejada viagem espacial. A autorização para a viagem é dada através de um carimbo que chancela a liberação do adulto sobre a curiosidade das crianças. O dia do Carimbador Maluco, em referência ao conteúdo musicado, promovia a presença das crianças no Raul Hacker Club, sob cuidado dos adultos e sem tolher as possibilidades inventivas delas, assumindo que aquele, inicialmente, não era um local para crianças, afinal ali ficam dispostos ferramentas, artefatos e produtos que poderiam significar risco para elas, quando manuseados sem supervisão intensa.

A sede do Raul Hacker Club era um espaço tipo sala com cerca de 10 metros quadrados, com duas janelas médias de vidro, dividido com uma pequena cozinha e um banheiro. Havia um 
sofá de dois lugares, uma grande mesa oval no centro da sala, um almofadão estilo pufe, algumas almofadas e banquetas plásticas, além de uma estante com livros e materiais de computação, um armário com chave e um organizador de madeiras com nichos nos quais havia sucatas e ferramentas. A cada encontro contava-se com a presença de quatro a sete crianças, na faixa etária entre 3 e 11 anos, sendo três delas integrantes da mesma família. No mínimo, duas pessoas adultas acompanhavam as crianças a cada encontro e as atividades propostas iam da desmontagem de peças de máquina antigas a brincadeiras com luzinhas de led (diodo emissor de luz), dentre outras.

Com o passar do tempo e a visibilidade que o projeto ganhou, foram inseridas atividades específicas do mundo hacker como oficina de criptografia e jogos on-line. A escolha das atividades sempre levava em conta a disponibilidade de materiais e de orientadores adultos, o tempo e os riscos para realizá-las, evitandose o uso de materiais de alto custo ou que pudesse significar qualquer risco para a saúde das crianças. Praticar a liberdade em um ambiente relativamente pequeno com crianças que não se conheciam ainda e no qual havia diversos materiais relativamente perigosos, exige planejamento e olhar atento, assim como exige o estabelecimento de relações de cuidado e confiança entre todos os envolvidos independentemente da idade. Aprendemos que é importante todos cuidarem de todos.

A presença frequente das crianças na sede teve como consequência, modificações na infraestrutura local, com vistas a garantir a segurança e a liberdade infantil. O armário de ferramentas foi fixado na parede, a uma altura de 1,5 metros do chão e uma parte das paredes recém pintadas foram cobertas com plástico adesivo, para que as crianças pudessem escrever nas paredes usando canetas de quadro branco sem danificar a pintura da sede. A linguagem escrita pelos membros para dar informes ou recados também foi modificada. Antes era comum encontrar palavrões ou palavras de tom pejorativo para se referir à sujeira no banheiro ou à louça que não foi lavada. Com a presença das crianças, essas palavras foram desaparecendo dos recados escritos, e substituídas por outras não pejorativas. Compreendemos, a partir de Michel de Certeau, que o cotidiano se constitui por sujeitos praticantes, ganhando destaque aqueles que praticam a arte das táticas: os imigrantes, as classes subalternas, as mulheres, as crianças, sempre 
o fraco na luta contra o forte. É preciso então, prestar atenção e investir nos estudos da vida cotidiana das pessoas comuns, desses produtores desconhecidos, consumidores que nas suas operações e usos criam práticas significantes. No momento em que as crianças são inseridas nesse "lugar de adulto" elas passam a ser pensadas, respeitadas, elas passam a transformar aquele espaço de alguma maneira, não só no aspecto físico como a mudança dos armários e cuidados com a segurança dos pequenos, mas também com a própria cultura local, com a linguagem utilizada no cotidiano, o cuidado em não dizer e escrever palavrões, o pensar aquelas crianças naquele espaço, que passa a ser delas também. Buscavase, como nos diz Barbosa e Horn (2008, p. 17):

Um espaço que ao mesmo tempo acolha e desafie as crianças, com a proposição de atividades que promovam a sua autonomia em todos os sentidos, a impregnação de todas as formas de expressão artística e das diferentes linguagens que possam ser promovidas junto a elas.

A partilha desses significados entre os participantes adultos a partir da chegada das crianças, produziu um sentimento de inclusão nelas (o sentir-se participar) e a inclusão de fato (ser participante) de ambos os lados. De um lado, as crianças diziam ser hackers, compreendiam a diferença entre quebrar coisas ou desmontá-las, interessavam-se pelos acontecimentos e pelas pessoas do espaço, queriam vestir a camisa com a logomarca e mostravam-se dispostas a partilhar o que sabiam, como por exemplo, ensinar um jogo infantil para pessoas adultas ou explicar como se modifica um brinquedo. Essas ações sinalizam para a instauração da participação como atitudes que importam, que fazem diferença. (SHIRKY, 2011)

De outro lado, adultos que não se imaginaram nessa convivência mais intensiva com crianças, propuseram atividades que, usualmente, não seriam pensadas para elas. O relato feito por Nekoone, integrante do Raul Hacker Club, em seu blog pessoal, expressa essa situação. Após realizar uma atividade de decifrar códigos com quatro crianças na faixa de cinco a dez anos de idade, nos conta:

Nunca achei que eu ensinaria criptografia para crianças, mas pasmem, eu fiz, claro que não foi sozinha, tive ajuda de duas pessoas sensacionais ka-san [...] e Geisinha [...], da [rede] Periférias, e não podemos esquecer delas, as crianças, que 
foram superlegais, entenderam rápido e me divertiram muito... (MENEZES, 2018, p. 104)

$\mathrm{O}$ ato de ensinar para crianças recebe destaque logo na primeira linha, como fato inusitado. Um exemplo de algo que o rapaz considerava impossível foi tornado possível quando convergiram a oportunidade, as condições e o desejo de ser realizado. O direcionamento para a diversão também aparece do lado do adulto, uma vez que ele também pode se divertir enquanto ensina, tanto quanto pode aprender.

O aprendizado do adulto, em situações como essa, não se relaciona a conteúdos conceituais, mas sim a conteúdos procedimentais e atitudinais específicos (ZABALA, 1998), relacionados ao modo como se direcionar para seus aprendizes, a como modular sua fala, a como se relacionar com o saber dos aprendizes que fazem perguntas simples, mas cujas respostas podem ser complexas. Em um dos encontros do projeto Crianças Hackers, realizado em 2015, um menino perguntou para um premiado professor de robótica "Tio, o que é movimento?" Essa pergunta deixou o professor desconcertado. Não porque ele desconhecesse a resposta, mas porque a pergunta inesperada foi feita por uma criança de três anos. O professor estava sentado no chão com um grupo de crianças de faixa etária variada, mostrando-lhes o funcionamento de um controle remoto de carrinho operado com software livre. Ao ouvir a pergunta, ele olhou para os lados procurando ajuda para encontrar uma resposta adequada, afinal, os conceitos de mecânica ou de cinética não caberiam naquele momento. Uma colega pedagoga, respondeu: - Movimento é "se mexer", ao que a criança ouviu e fez olhar de compreensão. Diante do olhar satisfeito do jovem aprendiz de três anos, o professor (aliviado) continuou a falar sobre seu invento enquanto as crianças brincavam com o artefato. Os processos de ensinar e aprender passam a ser mais horizontalizados, o coletivo e as redes passam a ser pontos de ancoragem muito importantes e significativos. A troca de saberes e conhecimentos ganham destaque em relação à hierarquia.

Nessas situações a inclusão dos envolvidos vai sendo forjada em pequenas e grandes atitudes que alteram os cotidianos: na mudança do ambiente e no movimento de se propor a ensinar, no adulto que escuta a criança e nos olhares de apoio e cumplicidade diante da dúvida. Incluir "[...] é a nossa capacidade de entender e reconhecer o outro e, assim, ter o privilégio de conviver e compartilhar com pessoas diferentes de nós". (MANTOAN, 2005) 
Os espaços-tempos de aprendizagem passam a ser outros, escancarando a crescente complexidade dos processos de aprender que agora estão enredados em várias teias de relações, praticantes e significados e que, por conseguinte, trazem a convergência de diversos outros espaços-tempos (ou contextos). O espaço do Raul Hacker Club, passa a ser um local instituinte de práticas contrahegemônicas, explicitadas através da construção e reorganização de linguagens outras, direcionadas ao atendimento de um público infantil, e às próprias ações que reordenam os saberes-fazeres desse cotidiano tornando-o profícuo espaço de criação, emancipação e compartilhamento de saberes.

\begin{abstract}
A figura atual de uma marginalidade não é mais a de pequenos grupos, mas uma marginalidade de massa; atividade cultural dos não produtores de cultura, uma atividade não assinada, não legível, mas simbolizada, e que é a única possível a todos aqueles que no entanto pagam, comprando-os, os produtosespetáculos onde se soletra uma economia produtivista. Ela se universaliza. Essa marginalidade se tornou a maioria silenciosa. (CERTEAU, 2008, p. 44)
\end{abstract}

As redes de aprender também vão sendo alteradas e se multiplicam. Felipe e sua mãe, discutiam sobre a biruta (mecanismo usualmente encontrado em aeroportos para sinalizar o sentido de deslocamento do vento), quais as suas funcionalidades, para que serve, nome do artefato etc. A mãe falou a ele que aprendeu sobre o dispositivo na escola, na antiga $4^{\text {a }}$ série na disciplina de Estudos Sociais, ao que o filho respondeu de imediato: "Eu aprendi com o Peixonauta", uma série de animação brasileira-canadense, produzida no Brasil e veiculado por um canal americano especializado em desenhos. Provavelmente o garoto tenha aprendido sobre o artefato em mais tenra idade que a própria mãe, pois concomitante ao período em que esteve na Educação Infantil, Felipe já estava em contato com a televisão a cabo e vídeos da internet. Igualmente, outras crianças com acesso amplo às tecnologias digitais, podem desenvolver saberes cujos pais não tiveram oportunidade de desenvolver quando tinham a mesma idade. Registramos em diário de campo a criança de 2 anos e 8 meses usando vocabulário em inglês no seu cotidiano para se referir a números e cores enquanto usava seus gizes de cera para colorir. Quando dois deles caem no chão, ela se refere aos objetos pelas cores em inglês. Além de contar 
seus brinquedos e cantar algumas músicas infantis, também já tenta acompanhar o gosto musical de seus pais, sendo que estes não são falantes da língua e nem a escola oferece tal conteúdo. A criança tem acesso aos canais infantis na rede Netflix e quando chega na escola ou em outros espaços de socialização, ela já vem com um repertório construído em diversas redes: familiar, amigos, escola, redes sociais, televisão, literatura etc.

Valorizar a historicidade de espaços e tempos desconsiderados, tidos sem importância dentro do cotidiano educativo é reconhecêlo na multiplicidade de interfaceamentos que o produzem, de construção de saberes, de lutas e barganhas, daquilo que de bom ou de ruim ali é constituído ou não, dos seus processos, das formas de participação, dos modos de fazer e pensar esses cotidianos.

O que favoreceu a criança de dois anos a aprender palavras em uma língua na qual seus pais não são nativos, foi o cuidado que esses tiveram em preparar o ambiente familiar com experiências que a estimulassem a vivenciar a língua inglesa com programas que lhe despertam o interesse. O que estimula Felipe a continuar com seus inventos é a sensibilidade de uma mãe que busca formas de deixá-lo livre para educar-se em casa. O que contribuiu para que o Raul Hacker Club tivesse seus espaços repensados para acolher crianças foi a ousadia de uma mãe em tentar criar para seu filho um espaço de aprendizagens que ela não poderia oferecer sozinha. Nenhuma dessas situações se deu à revelia da instituição escolar, mesmo sendo experienciadas em paralelo a ela. E não raro, as crianças aqui citadas já começam a questionar a organização escolar cujas práticas instituídas estão fortemente arraigadas, os modos de fazer, ser, estar, pensar, desejar, que nesse ambiente ainda se apresentam tão encapsulados, difíceis de serem acessados, atingidos e transformados.

A escola, até agora, caracteriza-se pela predominância do tempo racional, tempo imposto, uma estratégia vinda de cima para baixo (principalmente através de políticas públicas verticais), que fragmenta os processos e ritmos individuais, curiosidades e experiências, massificando-as, silenciando-as porque impõe a elas linearidade, organizando as atividades e os tempos segundo critérios externos que pouco dialogam com as singularidades de seus aprendizes. Ou seja, fica difícil prosseguir com uma escola que precisa seguir um currículo prescritivo, como uma lista de conteúdos a ser alcançada por todos ao mesmo tempo e do mesmo 
modo, quando as crianças já chegam com tantas experiências latentes e demandas não respondidas.

O contexto do digital exige uma visada conceitual extrema nas instituições educativas e no próprio conceito de educação. De um lado, estão as famílias cujos adultos empenham-se na sustentação material de suas existências, muitas vezes tomados por tantos trabalhos e afazeres que lhes falta tempo para olhar e ouvir suas crianças, para compartilhar com elas alguma aprendizagem ou experiência significativa. De outro, estão as instituições educativas formais, tais como a escola, com dificuldades em se atualizar, em se reinventar. Entre eles, estão iniciativas comunitárias diversas que tentam oferecer o que falta à escola e à família, o encontro entre adultos e crianças com a intenção de partilhar conhecimentos específicos e socialmente implicados. E dentre estes, estão pessoas que conhecem seu funcionamento, suas potencialidades e seus riscos e defendem que o saber tecnológico de ponta é um direito de todas e todos. Mas essas pessoas, os hackers - dentre os quais homens e mulheres - não estão diretamente ligados a instituições educativas e a visão negativa disseminada sobre sua cultura, não contribui para que estes compartilhem seus conhecimentos e talentos além de suas próprias comunidades. O desafio é hackear os espaços e as práticas instituídas na formação de redes de pessoas que compreendem o quanto a cultura hacker e a cultura infantil tem em comum, conectando-os através das brechas, e isso se faz no cotidiano.

\title{
Children, Adults and Hackers: Day-to-day and Technologies
}

\begin{abstract}
This article discusses about the children's day-to-day shared with the adults, faced with the prospect of digital culture and practices hackers developed from the proposal for interaction with participants of the project Children Hackers and their everyday life family. The word hacker is taken in the original sense referring to people with strong interest in technologies whose curiosity pushes their attitudes of playful way. The specific objectives are to describe and analyze the practices of shared learning between children and adults, in the face of content related to technology, in the construction and reflection on these experiences from their everyday life in the interaction with the digital culture. As participant research's constructs we present reports of activity and experiences in which children play the reinvention not only of physical spaces that passthrough restructuring but the ways of being and doing of adults who need to reflect and rebuild their practices in relation with the little ones. As a result, we can mention the urgent need to rethink the formal educational spaces, for highlighting the everyday experiences of
\end{abstract}


children and are more attentive to contemporary dynamics, which involve not only the insertion of digital technologies, but above all other ways of thinking, do relate, be, build and share knowledge.

Keywords: Children. Learning. Culture. Technology. Hackers

\title{
Niños y niñas, adultos y hackers: cotidianos y tecnologías
}

\begin{abstract}
Resumen: Este artículo tiene como objetivo discutir los cotidianos infantiles compartidos con los adultos, frente a la perspectiva de la cultura digital y de las prácticas hackers desarrolladas a partir de la propuesta de interacción con participantes del proyecto Niños Hackers y en sus cotidianos familiares. La palabra hacker es tomada en su sentido originario refiriéndose a personas con fuerte interés en tecnologías cuya curiosidad impulsa sus actitudes de forma lúdica. Los objetivos específicos están en describir y analizar las prácticas de aprendizaje compartido entre niños y personas adultas, frente a contenidos relacionados a tecnologías en sentido amplio, en la construcción y reflexión sobre esas vivencias a partir de sus cotidianos en la interacción con la cultura digital. Como constructos de la investigación participante presentamos relatos de actividades y vivencias en los que los niños protagonizan la reinvención no sólo de los espacios físicos que pasan por reestructuraciones, sino de los modos de ser y hacer de los adultos que necesitan reflexionar y reconstruir sus prácticas en la relación con los pequeños. Como resultados podemos mencionar la necesidad urgente de repensar los espacios educativos formales, para que valoren las experiencias cotidianas de los niños y estén más atentos a las dinámicas contemporáneas, que involucran no sólo la inserción de tecnologías digitales, sino principalmente otras maneras de pensar, hacer, relacionar, ser, construir y compartir conocimientos.
\end{abstract}

Palabras clave: Niños. Aprendizaje. Cultura. Tecnología. Hackers.

\section{Referências}

BARBOSA Maria Carmen Silveira; HORN, Maria da graça Souza. Projetos pedagógicos na educação infantil. Porto Alegre: Artmed, 2008.

BRANDÃO, Carlos Rodrigues; BORGES, Maristela Correa. A pesquisa participante: um momento da educação popular. Revista de Educação Popular, Uberlândia, v. 6, p.51-62. jan./dez. 2007.

BROUGÈRE, Gilles. A criança e a cultura lúdica. In: KISHIMOTO, Tizuco Morchida et al. (org.). O brincar e suas teorias. São Paulo: Cencage Learning, 2011. p. 19-32. Disponível em http://wenger-trayner. com/introduction-to-communities-of-practice/. Acesso em: $10 \mathrm{dez}$. 2016 .

CAZELOTO, Edilson. Inclusão digital: uma visão crítica. São Paulo: Senac São Paulo, 2008.

CERTEAU, Michel de. A invenção do cotidiano: 1. Artes do fazer. Tradução de Ephraim F. Alvez. 15. ed. Petrópolis, RJ: Vozes, 2008. 
CORDEIRO, Salete de Fátima Noro. Tecnologias digitais móveis e cotidiano escolar: espaços/tempos de aprender. Orientadora: Maria Helena Silveira Bonilla. 2014. 322 f. Tese (Doutorado em Educação) Faculdade de Educação, Universidade Federal da Bahia, Salvador, 2014.

FERRAÇO, Carlos Eduardo. Apresentação. In: FERRAÇO, Carlos Eduardo (org.). Cotidiano escolar, formação de professores(as) e currículo. 2. ed. São Paulo: Cortez, 2008. p. 07-14.

GEERTZ, Clifford. Interpretação das culturas. Tradução de The interpretation of cultures. Rio de Janeiro: LTC, 2008.

GOLDANI, Ana Maria. As famílias no Brasil contemporâneo e o mito da desestruturação. Cadernos PAGU, Campinas, p. 1-44. Disponível em: http://www.bibliotecadigital.unicamp.br/ document/?code $=50135 \&$ opt $=1$. Acesso em: 8 jul. 2018.

HIMANEN, Pekka. A ética dos hackers e o espirito da era da informação. Tradução de Fernanda Wolf. Rio de Janeiro: Campus, 2001.

IBGE. Indicadores IBGE (pesquisa mensal de emprego): o trabalho da mulher principal responsável no domicílio, 2006. Disponível em: https://biblioteca.ibge.gov.br/visualizacao/livros/liv101551_ informativo.pdf Acesso em: 2 ago. 2018.

IBGE. Indicadores sociais das mulheres no Brasil, 2018. Disponível em: https://biblioteca.ibge.gov.br/visualizacao/livros/liv101551_ informativo.pdf Acesso em: 02 ago. 2018.

MANTOAN, Maria Teresa Eglér. Inclusão é o privilégio de conviver com as diferenças. Nova Escola, São Paulo, n. 182. Maio, 2005.

Disponível em https://www.inclusive.org.br/arquivos/50. Acesso em: 16 jul. 2017.

MENEZES, Karina Moreira. Pirâmide da Pedagogia Hacker $=[$ Vivências do (In)Possível]. 2018.180 f. Tese (Doutorado em Educação) - Faculdade de Educação da Universidade Federal da Bahia, Salvador, 2018.

Orientador: Nelson De Luca Pretto.

MOILANEN, Jarkko. Emerging Hackerspaces-Peer-Production Generation. Open Source Systems: Long-Term Sustainability. [S. 1.]:

Springer, 2012. p. 94-111. Disponível em: https://pdfs.semanticscholar. org/ab55/e6eaf54450a488ab7bebf96f09e5c978b145.pdf. Acesso em: 10 dez. 2016.

PAIS, José Machado. Vida cotidiana: enigmas e revelações. São Paulo: Cortez, 2003.

PRETTO, Nelson De Luca. O desafio de educar na era digital: educações. Revista portuguesa de educação, Braga, v. 24, n. 1, p. 95-118, 2011. Disponível em: http://revistas.rcaap.pt/rpe/article/view/3042. Acesso em: 8 jul. de 2018.

RAYMOND, Eric Steven. How to become a hacker. 2001. Disponível em http://catb.org/ esr/faqs/hacker-howto.html. Acesso em: 2 mar. 2015. 
SHIRKY, Clay. A cultura da participação: criatividade e generosidade no mundo conectado. Traduzido por: Celma Portocarrero. Rio de Janeiro: Zahar, 2011.

ZABALA, Antoni. A prática educativa: como ensinar. Porto Alegre: Editora Artes Médicas Sul Ltda., 1998.

Submetido em: 10/08/2018 Aceito em: 26/06/2019 